\title{
Ebriedad, fernandismo popular y represión en Oaxaca (1824-1833)*
}

\section{Drunkenness, Popular Fernandism and Repression in Oaxaca (1824-1833)}

\author{
Eliud SANTIAGO APARICIO \\ https://orcid.org/0000-0002-6830-7346 \\ Universidad Autónoma Metropolitana-Iztapalapa (México) \\ odiseo1945@gmail.com
}

\section{Resumen}

Durante la guerra de Independencia de México (1810-1821), la Intendencia de Oaxaca mostró gran lealtad al rey Fernando VII, pese a la ocupación de la entidad por fuerzas insurgentes durante dos años. Y, una vez consumada la Independencia en 1821, ciertos sectores populares continuaron expresando lealtad a la Corona española. El presente artículo analiza esas manifestaciones en ambientes de ebriedad y las reacciones de la sociedad y el gobierno, basado en la investigación de expedientes judiciales. Miembros de la sociedad interpusieron denuncias judiciales, mientras que el gobierno se propuso erradicar todo símbolo que remitiera al pasado colonial.

Palabras clave: ebriedad, Fernando VII, infidencia, Oaxaca, popular

\begin{abstract}
During the Mexican War of Independence (1810-1821), the Oaxaca Intendancy showed great loyalty to the Spanish King Fernando VII, despite the occupation of its territory by the insurgent forces during two years. And, once Mexico's independence was accomplished in 1821, certain popular sectors kept showing loyalty to the Spanish Crown. Based on research of judicial files, this article analyzes diverse outcries of adherence to the Spanish Crown in drunken situations in the Intendancy of Oaxaca, as well as the reactions of both members of society and the Mexican government, the former filing lawsuits, and the latter thriving to eradicate any clue of the colonial past.
\end{abstract}

Keywords: drunkenness, Fernando VII, disloyalty, Oaxaca, popular fernandismo

* Agradezco a la Fundación uAbjo y a la Fundación Alfredo Harp Helú el apoyo económico proporcionado para realizar este artículo. Igualmente reconozco las sugerencias de Daniela Traffano, Selene García, Francisco Ruíz, Juan Yañez, Maribel Uraga, Brian Connaughton, Peter Guardino y del Seminario México-España del Colmex.

Recepción: 18 de agosto de 2020 | Aceptación: 20 de noviembre de 2020 


\section{Introducción}

La literatura sobre los españoles y lo español en el México de la primera mitad del siglo XIX resulta abundante. Los estudios de Harold Sims abordaron las expulsiones de los españoles (1827, 1829 y 1833), las contrarrevoluciones españolas y las manifestaciones de desprecio y apoyo hacia ellos desde la masonería mexicana y el motín del Parián de $1828 .{ }^{1}$ Sus investigaciones son nodales aunque también objeto de discusión historiográfica, pues Jesús Ruiz de Gordejuela cuestiona la cifra de españoles expulsados afirmando que su número no fue tan alto. ${ }^{2}$ Leticia Gamboa Ojeda, Emilio Maceda y Claudia Patricia Pardo Hernández trabajaron la expulsión de los españoles y sus repercusiones socioeconómicas en Puebla y la Ciudad de México. ${ }^{3}$ Antonia Pi Suñer, en cambio, abordó la deuda española como un requisito para que España reconociera la Independencia de México. ${ }^{4}$

Las investigaciones desde la perspectiva ideológica son múltiples. Romeo Flores Caballero, Erika Pani, Enrique Plasencia de la Parra, Miguel Soto Estrada, Marco Antonio Landavazo, Tomás Pérez Vejo, Fernando Jesús Cab Pérez, Ángel Omar May González y Romana Falcón analizaron las diversas expresiones de animadversión dirigida hacia los españoles a través de la prensa, folletos, discursos cívicos, pasquines y la violencia popular. ${ }^{5}$ En

${ }^{1}$ Harold Sims, La expulsión de los españoles de México (1821-1828) (México: Secretaría de Educación Pública, 1985), 1-300; Harold Sims, Descolonización en México. El conflicto entre mexicanos y españoles (1821-1831) (México: Fondo de Cultura Económica, 1982), 1-259; y Harold Sims, La reconquista de México, la historia de los atentados españoles, 1821-1830 (México: Fondo de Cultura Económica, 1980), 1-175.

${ }^{2}$ Jesús Ruiz de Gordejuela Urquijo, La expulsión de los españoles de México y su destino incierto, 1821-1836 (Sevilla: Consejo Superior de Investigaciones Científicas/Escuela de Estudios Hispano-Americanos/Universidad de Sevilla/Diputación de Sevilla, 2006), 97.

${ }^{3}$ Leticia Gamboa Ojeda y Emilio Maceda, "La expulsión de los españoles en Puebla y el perfil de los exceptuados, 1827-1828”, Revista de Indias, n. 228 (2003): 375-394, https://doi. org/10.3989/revindias.2003.i228.443; y Claudia Patricia Pardo Hernández, “Tres expulsiones fallidas de la ciudad de México entre 1828 y 1847: los españoles, los franceses y los estadounidenses", Ulúa, n. 4 (julio-diciembre 2004): 9-32.

${ }^{4}$ Antonia Pi-Suñer Llorens, La deuda española en México. Diplomacia en torno a un problema financiero, 1821-1890 (México: El Colegio de México/Universidad Nacional Autónoma de México, Facultad de Filosofía y Letras, 2006), 49.

${ }^{5}$ Romeo Flores Caballero, Revolución y contrarrevolución en la independencia de México, 1767-1867 (México: Océano, 2009), 145-239; Erika Pani, "De coyotes y gallinas. Hispanidad, identidad nacional y comunidad política durante la expulsión de españoles”, Revista de Indias, n. 228 (2003): 355-374, https://doi.org/10.3989/revindias.2003.i228.442; Enrique Plasencia de la Parra, Independencia y nacionalismo a la luz del discurso conmemorativo (1825-1867) 
términos generales, tal sentimiento desvirtuaba, deslegitimaba la conquista espiritual y militar de los españoles, estigmatizaba la participación realista durante la guerra de Independencia como atroz y denunciaba una posible reconquista.

Existen importantes trabajos sobre asociaciones políticas que determinaron su posicionamiento antiespañol o proespañol en el México independiente. En la ciudad de Oaxaca, por ejemplo, Peter Guardino estudió dos grupos: los “aceites" y los "vinagres". Los primeros eran respaldados por españoles y algunos criollos; mientras los segundos, por criollos, mestizos e indígenas. Los "aceites" se denominaban así porque si se combinaban ambos líquidos el aceite siempre quedaba por encima del vinagre. ${ }^{6}$ En Texcoco también apareció un grupo autodenominado "los americanos" cuyo perfil era antiespañol y quienes apodaron a sus adversarios como los "gachupines" o "gallicoyotes" porque en sus filas militaban españoles y criollos pro-españoles. Casos similares sucedieron en Morelia y Aguascalientes. ${ }^{7}$

(México: Consejo Nacional para la Cultura y las Artes, 1991), 17-40; Miguel Soto Estrada, "Imágenes y estereotipos durante la expulsión de los españoles de México", en México y España en el siglo XIX. Diplomacia, relaciones triangulares e imaginarios nacionales, coord. de Agustín Sánchez Andrés y Raúl Figueroa Esquer (Morelia: Universidad Michoacana de San Nicolás de Hidalgo, Instituto de Investigaciones Históricas/Instituto Tecnológico Autónomo de México, 2003), 205; Marco Antonio Landavazo, "Imaginarios encontrados. El antiespañolismo en México en los siglos xıx y xx”, Tzintzun. Revista de estudios Históricos, n. 42 (julio-diciembre 2005): 33-48; Tomás Pérez Vejo, "Cuando los españoles estuvieron a punto de dejar de ser gachupines”, en Enemigos íntimos. España, lo español y los españoles en la configuración nacional hispanoamericana 1810-1910, coord. de Tomás Pérez Vejo (México: El Colegio de México, 2011), 213-244; Fernando Jesús Cab Pérez y Ángel Omar May González, "El águila contra el león. Construcción del discurso antihispanista y republicano en la prensa campechana (1824-1831)”, Signos Históricos, n. 43 (enero-junio 2020): 254-299; y Romana Falcón, Las rasgaduras de la descolonización. Españoles y mexicanos a mediados del siglo XIX (México: El Colegio de México, 1996), 1-368.

${ }^{6}$ Peter Guardino, El tiempo de la libertad. La cultura política popular en Oaxaca, 1750-1850 (Oaxaca: Universidad Autónoma Benito Juárez de Oaxaca/Universidad Autónoma Metropolitana-Iztapalapa/El Colegio de Michoacán/El Colegio de San Luis Potosí/Congreso del Estado de Oaxaca, 2009), 295-297.

7 Diana Birrichaga Gardida, "Facciones y movilización electoral en Texcoco, 1820-1828", en Campañas, agitación y clubes electorales. Organización y movilización del voto en el largo siglo XIX mexicano, coord. de Fausta Gantús y Alicia Salmerón (México: Instituto Nacional de Estudios Históricos de las Revoluciones de México/Instituto de Investigaciones Dr. José María Luis Mora, 2019), 164. Para el caso de Morelia, véase Carlos Juárez Nieto, "Ayuntamiento y oligarquía en Valladolid de Michoacán (1808-1824)”, en El poder y el dinero. Grupos y regiones mexicanos en el siglo XIX, coord. de Beatriz Rojas (México: Instituto de Investigaciones Dr. José María Luis Mora, 1999), 69-70. Para Aguascalientes véase Beatriz Rojas, “Aguascalientes y Zacatecas, 1821-1835. ¿Una política compartida?”, en El poder y el dinero. 
Este breve repaso historiográfico sugiere que, con excepción de los grupos políticos pro-españoles como los "aceites" o los "gallicoyotes", los mexicanos eran partidarios de expulsar a los españoles y contrarios a España, irrumpiendo así con su legado colonial y monarquista. Pese a los esfuerzos de estos investigadores quienes contribuyen a entender el complejo proceso que los españoles enfrentaron tras la Independencia así como el establecimiento de relaciones diplomáticas entre la antigua metrópoli y el nuevo país, falta estudiar por qué algunos mexicanos, especialmente desde la perspectiva de los sectores populares, continuaron simpatizando con la Corona. ${ }^{8}$

En este sentido, el presente artículo analiza por qué determinados sectores populares oaxaqueños esperaban el retorno de la monarquía española y cómo fue la respuesta de las autoridades locales ante tales manifestaciones de infidencia. ${ }^{9}$ Algunas expresiones resultaron ser palabras, testimonios materiales o símbolos de adhesión hacia Fernando VII. Éstas tendían a ser cuestiones aisladas y esporádicas que sucedieron cuando las personas estaban bajo el influjo del alcohol o alegaron estarlo como una medida para recuperar su libertad. La postura de las autoridades

Grupos y regiones mexicanos en el siglo XIX, coord. de Beatriz Rojas (México: Instituto de Investigaciones Dr. José María Luis Mora, 1999), 101.

${ }^{8}$ Como señala Clara E. Lida, el término "clases populares" o "sectores populares" es objeto de discusión porque "su condición esencial era heterogénea y variable, y que se redefinía según cada momento, cada lugar, cada problema y cada conflicto”. Clara E. Lida, "¿Qué son las clases populares? Los modelos europeos frente al caso español en el siglo XIX", Historia Social, n. 27 (1997): 5. Torcuato Di Tella, por su parte, empleaba el término de "clases peligrosas" que estaban integradas por tres grupos "inferiores" o populares. En primer lugar los artesanos, pequeños comerciantes o mineros con cierta estabilidad económica. Los segundos eran individuos menos vinculados a sus trabajos y se desempeñaban como jornaleros ocasionales, mozos o vendedores ambulantes. Los últimos eran el pueblo "más bajo e inestable" también conocido como léperos o vagos. Torcuato Di Tella, "Las clases peligrosas a comienzos del siglo xix en México", Desarrollo Económico, n. 48 (enero-marzo 1973): 761791, https://doi.org/10.2307/3466303. Dicho lo cual, tomaré prestada la propuesta de Di Tella y estudiaré a los tres tipos de individuos que conformaron los "grupos inferiores" o "populares" y su relación con el fernandismo.

${ }^{9}$ En la Nueva España, "infidencia” significaba "no ser fiel a la Corona española”. Andrés del Castillo, "Acapulco, presidio de infidentes, 1810-1821", en La independencia en el sur de México, coord. de Ana Carolina Ibarra (México: Universidad Nacional Autónoma de México, Instituto de Investigaciones Históricas/Fideicomiso Felipe Teixidor y Monserrat Alfau de Teixidor, 2017), 161. Durante la República federal continuó utilizándose la palabra infidencia para señalar los movimientos centralistas y contrarrevolucionarios que atentaban contra el poder hegemónico. Para el presente estudio, la emplearé sólo para referirme al fernandismo. 
oaxaqueñas, entonces, fue la reconciliación más que el escarmiento ejemplar. Escogí Oaxaca porque, a diferencia de otros puntos del país, existe abundante información sobre procesos judiciales y castrenses contra el fernandismo de los sectores populares. ${ }^{10}$

El presente artículo está dividido en tres secciones. La primera sintetiza el fernandismo oaxaqueño durante la guerra de Independencia como una postura dominante durante el conflicto. La segunda estudia la relación entre ebriedad e inclinación hacia la Corona. El alcoholismo fue nodal para pronunciar palabras a favor de la Corona, ya que todos los acusados estaban borrachos cuando lo hicieron. La tercera representa un estudio de caso que gracias a su riqueza permite conocer los mecanismos de defensa que los imputados empleaban para elaborar su alegato frente a un proceso judicial o militar.

Fernandismo y guerra en la intendencia de Oaxaca 1808-1821

Después de que Napoleón Bonaparte destronara a Carlos IV, colocara a su hermano en el trono español y encarcelara a la familia real en 1808, las muestras de adhesión hacia Fernando VII, hijo de Carlos IV, se multiplicaron. Poemas, sermones y donaciones económicas fueron realizados en su honor en diversas partes del virreinato como en Oaxaca. Ampliamente se le conoció como "El Deseado" y su imagen fue edificada "en un estatuto muy cercano a lo sagrado". ${ }^{11}$ El virrey José de Iturrigaray, por su parte, convocó a una junta para discutir el futuro del virreinato pero fue aprehendido y depuesto. Con tal noticia, la intendencia de Oaxaca, conformada por una élite española dedicada al comercio de la grana cochinilla y de diversos productos textiles, extremó la vigilancia contra posibles amenazas y juró lealtad a Fernando VII. ${ }^{12}$

${ }^{10}$ No quiero decir que todos los oaxaqueños del México independiente fueran partidarios del retorno del rey de España, sino que los acervos históricos del estado permitieron estudiar el fernandismo con cierta holgura. Entiendo fernandismo como una postura que abogaba por el retorno de la Corona. Por otro lado, excluí la participación española de la infidencia porque es objeto de otro estudio.

${ }^{11}$ Marco Antonio Landavazo, "La sacralización del rey. Fernando VII, la insurgencia novohispana y el derecho divino de los reyes”, Revista de Indias, n. 221 (2001): 68, https:// doi.org/10.3989/revindias.2001.i221.483.

${ }^{12}$ Carlos Sánchez Silva, "Los cabildos civil y eclesiástico de la ciudad de Oaxaca ante la invasión insurgente, 1812-1814”, La Guerra de Independencia en Oaxaca. Nuevas perspectivas, 
En 1810 estalló la guerra de Independencia en Nueva España. Muchos insurgentes señalaron que la rebelión era a favor del rey y la religión. Algunos, incluso, creyeron que el mismo Fernando VII estaba en el Bajío liderando la insurgencia. ${ }^{13}$ Los rebeldes se declararon en contra de los españoles quienes se decía eran aliados de los franceses que pretendían entregar el reino a José Bonaparte, el monarca impuesto. Los realistas, por su parte, reafirmaron su devoción a Fernando VII al tiempo que deslegitimaron la rebelión caracterizándola como un intento bonapartista para conquistar la América española. ${ }^{14}$ En la intendencia de Oaxaca, Antonio Bergosa y Jordán, obispo electo de Oaxaca, formó regimientos liderados por eclesiásticos conocido por el nombre de "ejército de la mermelada", debido al color de su uniforme. En sus cartas pastorales señaló a Miguel Hidalgo como "traidor", "hereje” y "apóstata". Condenó la insurgencia, ordenó a los eclesiásticos de su obispado seguir sus pasos y respaldó la excomunión que el obispo de Michoacán hizo contra el cura de Dolores. ${ }^{15}$ No es casualidad que Carlos Sánchez Silva lo llame "el principal defensor de la causa realista en la intendencia". ${ }^{16}$

El cura Hidalgo, por su parte, encomendó a José María Armenta y Miguel López revolucionar la intendencia oaxaqueña pero fueron descubiertos, ejecutados y sus cadáveres decapitados y expuestos al público como escarmiento. ${ }^{17}$ Pese a los esfuerzos realistas por proteger la intendencia, en 1812 la ciudad de Oaxaca cayó en manos del cura José María Morelos y Pavón. Tras el triunfo se realizó una fiesta en honor a Fernando VII en la

coord. de Carlos Sánchez Silva (Oaxaca: Universidad Autónoma Benito Juárez de Oaxaca/ Comisión Permanente de Cultura de la LXI Legislatura del H. Congreso del Estado de Oaxaca/Universidad Autónoma Metropolitana, 2010), 67.

${ }^{13}$ Eric Van Young, La otra rebelión. La lucha por la independencia de México, 1810-1821 (México: Fondo de Cultura Económica, 2010), 23.

${ }^{14}$ Marco Antonio Landavazo, Nacionalismo y violencia en la Independencia de México (Toluca: Fondo Editorial Estado de México, 2012), 31-33.

${ }^{15}$ Manuel Esparza, "La Iglesia de Oaxaca en tiempo de la Independencia. El obispo Bergosa y Jordán”, en La Guerra de Independencia en Oaxaca. Nuevas perspectivas, coord. de Carlos Sánchez Silva (Oaxaca: Universidad Autónoma Benito Juárez de Oaxaca/Comisión Permanente de Cultura de la LXI Legislatura del H. Congreso del Estado de Oaxaca/Universidad Autónoma Metropolitana, 2010), 52; y Brian R. Hamnett, Revolución y contrarrevolución en México y el Perú (liberalismo, realeza y separatismo 1800-1824) (México: Fondo de Cultura Económica, 1978), 171.

${ }^{16}$ Sánchez, "Los cabildos..., 72.

${ }^{17}$ Guardino, El tiempo..., 213. 
cual "se ratificaban sus vínculos con la monarquía". ${ }^{18}$ En la intendencia de Oaxaca antes y durante la ocupación rebelde, lejos de execrar al monarca se reforzaron los vínculos de fidelidad hacia él, convirtiéndolo en objeto de veneración, estima y respeto a través de juras, fandangos y la militarización de la ciudad.

En 1813 el cura Morelos salió rumbo a Acapulco. Las fricciones internas entre los mismos dirigentes rebeldes así como la actividad contrarrevolucionaria de algunos realistas que permanecieron en la ciudad debilitaron la defensa y la reconquista enemiga resultó fácil. ${ }^{19}$ Mientras tanto en España, en 1812 las Cortes de Cádiz publicaron la Constitución y dos años después el monarca regresó disolviendo la Carta Magna. Esto lo hizo impopular en ciertos lugares del virreinato porque algunos ahora lo llamaban "Imbécil" o "Indigno". No pocos insurgentes expresaron el deseo de Independencia y animadversión hacia el rey porque había regresado "napoleonizado" o "afrancesado", como lo supuso el cura Morelos en 1815. ${ }^{20}$ La imagen de Fernando VII comenzaba a ser ambivalente pero en Oaxaca parecía ser todavía del agrado de los habitantes. Tras reconquistar la capital de la intendencia en 1814, Melchor Álvarez Thomas, jefe realista, señaló que los oaxaqueños, pese a la presencia rebelde, todavía daban fuertes muestras de adhesión hacia el monarca. Con la restitución de la Constitución en 1820, Fernando VII volvía a ser apreciado por muchos novohispanos quienes creían que una monarquía constitucional sería el mejor camino para el derrotero de los pueblos. ${ }^{21}$

¿Qué sucedió en el resto de la Intendencia de Oaxaca durante la guerra de Independencia? Como señala Brian Hamnett, en términos generales se mantuvo leal a la Corona, salvo algunos levantamientos indígenas que

${ }^{18}$ Ana Carolina Ibarra, "La experiencia insurgente en Oaxaca”, en La guerra de Independencia en Oaxaca. Nuevas perspectivas, coord. de Carlos Sánchez Silva (Oaxaca: Universidad Autónoma Benito Juárez de Oaxaca/Comisión Permanente de Cultura de la LXI Legislatura del H. Congreso del Estado de Oaxaca/Universidad Autónoma Metropolitana, 2010), 22-32.

${ }^{19}$ Margarita Dalton, Breve historia de Oaxaca (México: Fondo de Cultura Económica/El Colegio de México/Fideicomiso Historia de las Américas, 2004), 132-133.

${ }^{20}$ Sobre el supuesto afrancesamiento de Fernando VII, véase Alfredo Ávila y Gabriel Torres Puga, "Retóricas de la xenofobia: franceses y gachupines en el discurso político y religioso de Nueva España (1760-1821)”, 20/10 Memoria de las Revoluciones en México, n. 2 (septiembre-noviembre 2008): 36-43.

${ }^{21}$ Marco Antonio Landavazo, La máscara de Fernando VII. Discurso e imaginario monárquicos en una época de crisis. Nueva España, 1808-1822 (México: El Colegio de México/ Universidad Michoacana de San Nicolás de Hidalgo/El Colegio de Michoacán, 2011), 1-357. Para el caso de Oaxaca, véase especialmente la página 269. 
poseían, más bien, un carácter de descontento contra los abusos económicos de los españoles comerciantes pero que de ningún modo fueron masivos. ${ }^{22}$ Posteriores investigaciones han ampliado esta perspectiva con la participación de la guerra de guerrillas. Si bien los guerrilleros no desaparecieron durante toda la guerra, tampoco se hicieron con el control de extensos territorios. En la Mixteca, por ejemplo, las partidas acosaban a los trenes militares e intentaron romper las comunicaciones con la intendencia de Puebla. Fortalecieron sus acciones con la incursión del cura Morelos en 1812. Pese a la diferencia de experiencia en el campo de batalla o de la guerra de guerrillas, los historiadores concuerdan con que la salida del cura de Morelos en 1813 marcó el inicio de la reconquista realista en Oaxaca. La muerte de Morelos en 1815 fue otro duro golpe al movimiento insurgente. En 1817 la rendición de Miguel Martínez en el cerro de San Miguel de Silacayoápam, en la sierra mixteca, debilitó la rebelión. ${ }^{23}$ Un año después las tropas rebeldes salieron de Villa Alta hacia Cosamaloapan, intendencia de Veracruz ${ }^{24}$ minimizando todavía más su presencia.

En 1821 Agustín de Iturbide proclamó el plan de Iguala y el de Córdoba ofreciendo el reino a un miembro de la casa real española. En el virreinato hubo disensión. Rodrigo Moreno señala que el movimiento Trigarante fue un "proceso bélico" nutrido de capitulaciones, asedios de ciudades y estrategias político-militares bien definidas. ${ }^{25}$ En efecto, la fidelidad oaxaqueña hacia la Corona desembocó en múltiples batallas entre realistas

22 Hamnett, Revolución..., 170-171.

${ }^{23}$ Francisco López Bárcenas, “Los pueblos mixtecos en la guerra de Independencia”, en La guerra de Independencia en Oaxaca. Nuevas perspectivas, coord. de Carlos Sánchez Silva (Oaxaca: Universidad Autónoma Benito Juárez de Oaxaca/Comisión Permanente de Cultura de la LXI Legislatura del H. Congreso del Estado de Oaxaca/Universidad Autónoma Metropolitana, 2010), 112-120; y Luis Alberto Arrioja Díaz Viruell y Carlos Sánchez Silva, "Melchor Álvarez Thomas, comandante general de la intendencia de Oaxaca, 1813-1818”, coord. de Jaime Olveda, Los comandantes realistas y la guerra de Independencia (Zapopan: El Colegio de Jalisco, 2010), 233-241.

${ }^{24}$ Luis Alberto Arrioja Díaz Viruell, "Problemas y coyunturas internas. Una visión del sexenio absolutista desde Villa Alta (Oaxaca)”, en La guerra de Independencia en Oaxaca. Nuevas perspectivas, coord. de Carlos Sánchez Silva (Oaxaca: Universidad Autónoma Benito Juárez de Oaxaca/Comisión Permanente de Cultura de la LXI Legislatura del H. Congreso del Estado de Oaxaca/Universidad Autónoma Metropolitana, 2010), 183.

${ }^{25}$ Rodrigo Moreno Gutiérrez, La Trigarancia. Fuerzas armadas en la consumación de la independencia, Nueva España, 1820-1821 (México: Universidad Nacional Autónoma de México, Instituto de Investigaciones Históricas/Fideicomiso Felipe Teixidor y Monserrat Alfau de Teixidor, 2016), 256. 
y trigarantes en los últimos días del virreinato, siendo la toma de Yanhuitlán, Huajuapán, Tlaxiaco, Etla y la ciudad de Oaxaca por el jefe Trigarante Antonio de León, algunas de las más importantes en la intendencia de Oaxaca. ${ }^{26}$

Tras este breve repaso cronológico del conflicto independentista en la intendencia de Oaxaca, salen a flote dos elementos muy importantes. A diferencia de otras intendencias como Michoacán o Guanajuato, donde insurgentes y realistas se declararon una guerra a muerte, ${ }^{27}$ en Oaxaca las operaciones militares de los insurgentes se limitaron a acciones guerrilleras y a una breve ocupación del corazón de la intendencia. Los realistas mantuvieron un mayor control militar del territorio que dio pie al segundo elemento. La intendencia de Oaxaca se mostró, antes y después de la ocupación del cura Morelos, como un baluarte del realismo y de Fernando VII. Esta actitud fue uniforme en casi toda la intendencia oaxaqueña lo que sugiere, a diferencia de otras intendencias, mayor lealtad al rey en tiempos de incertidumbre y de guerra. ¿Tuvo vigencia después de 1821 ?

\section{Ebriedad y fernandismo popular (1824-1836)}

En el presente apartado estudio la continuidad del fernandismo en el Oaxaca republicano y federalista. Se advierte que, durante los momentos más álgidos de crisis político-militar, apareció mayor adhesión hacia Fernando VII. En 1827 fue descubierta la conspiración del fraile Joaquín Arenas y comenzaron las expulsiones de los españoles (1827, 1829 y 1833). En Oaxaca esto se tradujo en un aumento de acusaciones contra individuos que se expresaron a favor de la Corona, aunque, cabe aclararlo, la denuncia en algunos casos sirvió para saldar viejas rencillas entre los propios vecinos de una localidad. ${ }^{28}$

${ }^{26}$ Alejandra González Leyva, "Las fortificaciones de Yanhuitlán durante la guerra de Independencia”, en La guerra de Independencia en Oaxaca. Nuevas perspectivas, coord. de Carlos Sánchez Silva (Oaxaca: Universidad Autónoma Benito Juárez de Oaxaca/Comisión Permanente de Cultura de la LXI Legislatura del H. Congreso del Estado de Oaxaca/Universidad Autónoma Metropolitana, 2010), 147.

27 "Plan de devastación suscrito por Morelos, Liceaga y el Doctor Cos”, en Escritos políticos, José María Cos, selección, introducción y notas de Ernesto Lemoine Villicaña (México: Universidad Nacional Autónoma de México, 1967), 154-155; y Juan Ortiz Escamilla, Guerra y gobierno. Los pueblos y la independencia de México, 1808-1825 (México: El Colegio de México/Instituto de Investigaciones Dr. José María Luis Mora, 2014), 19-244.

${ }^{28}$ Se desecharon los siguientes casos porque las acusaciones resultaron falsas, según las indagaciones judiciales. Manuel Gómez acusó a Andrés Sánchez de haber dicho “que él sabía 
En 1829, volvió a aparecer un impulso positivo hacia Fernando VII cuando el brigadier Isidro Barradas intentó reconquistar México. Tras su fracaso decayeron en Oaxaca las manifestaciones del retorno del rey.

Consumada la Independencia, en diversos puntos del país decenas de españoles y mexicanos leales a la Corona no juraron la Independencia. ${ }^{29}$ Sin embargo, aceptaron a regañadientes la Independencia esperando el arribo del mismo Fernando VII o de algún otro Borbón, pues así lo estipulaban los tratados de Iguala y de Córdoba. ${ }^{30}$ Esto no sucedió y Agustín de Iturbide ascendió al poder en 1822. Lo anterior tampoco significó un consenso político entre todos los mexicanos. Ciertas personas aceptaban la emancipación mientras otras deseaban el retorno de la Corona. La figura de Fernando VII, para algunos, se volvió la de un tirano despreciable pero, para otros, todavía era "El Deseado".

La transición entre monarquía y republicanismo resultaba todavía más compleja dado el enorme bagaje cultural que los mexicanos heredaron de la colonia: lengua, religión y fidelidad hacia el rey. La república dio continuidad a los dos primeros elementos pero emprendió una campaña para erradicar aquello que representaba la monarquía. Bustos, estatuas, pinturas y todo símbolo del antiguo régimen fueron removidos, destruidos

manejar las armas no como yo para la defensa de su rey y no que lo que ahora se hace no vale nada”. Sin embargo, el imputado demostró ser contrario a España porque sirvió bajo las banderas insurgentes con Valerio Trujano y más tarde con Morelos. Sánchez fue absuelto. "Año de 1827. Sumaria averiguación en contra de Andrés Sánchez por ultrajes a las autoridades legalmente constituidas”, Casa de la Cultura Jurídica en Oaxaca (en adelante ccJo), Juzgado de Primero de Distrito, exp. 100, f. 1-72. En 1827 sucedió un caso muy similar. José de Villar acusó a José Nicolás Alderete, alcalde de Miahuatlán, de ser aliado del conspirador español y dieguino Joaquín Arenas. El jurado dictaminó "maliciosa y temeraria la acusación" y falló a favor de Alderete. "Año de 1827. Criminal contra el C. Nicolás Alderete vecino de Miahuatlán por varios delitos", ccJo, Juzgado de Primero de Distrito, exp. 87, f. 1-48. Otros casos: "Año de 1829. Criminal contra Sortenio Aguilar (alias) el Chorriado por haber contestado al quien vive la expresión escandalosa de España”, ccJo, Juzgado de Primero de Distrito, exp. 18, f. 1-18; "Año de 1830. Criminal contra Matías Gutiérrez vecino de Coixtlahuaca, por el delito de infidencia”, ссло, Juzgado de Primero de Distrito, 1830, exp. 176, f. 1-35 y “Año de 1827. Expediente contra el Sr. José Suárez acusado de infidente”, ccjo, Juzgado de Primero de Distrito, 1827, exp. 99, f. 1-20.

${ }^{29}$ Para el caso de San Luis Potosí, véase Gabriela Bernal, "Se oyen voces. Rumor y miedo en la ciudad de San Luis Potosí, 1808-1811”, en Entre rumores, ejércitos rebeldes, ansiedad impresa y representaciones épicas. Estudios sobre la Independencia y la Revolución en San Luis Potosí, coord. de Moisés Gámez (San Luis Potosí: El Colegio de San Luis Potosí/LIX Legislatura del H. Congreso del Estado de San Luis Potosí/Secretaría de Cultura del Gobierno del Estado de San Luis Potosí, 2012), p. 28.

${ }^{30}$ Landavazo, La máscara de Fernando VII..., 304-305. 
o sustituidos por manifestaciones republicanas. ${ }^{31}$ Una de las herramientas más recurrentes para hacer del antiguo súbdito un ciudadano, fue el discurso cívico. Entre una misa con tedeum, baile, verbena y teatro, un orador daba un discurso cívico en la plaza principal, recordaba las gestas de Hidalgo y de Morelos, resaltaba los beneficios del federalismo, pero también estigmatizaba la monarquía y la presencia española. ${ }^{32}$ En Oaxaca, Juan José Quiñones temía que el país fuera gobernado una vez más por una "nación tan imbécil como España". ${ }^{33}$

En 1827 proliferaron opiniones favorables a la expulsión de los españoles tras ser descubierta la conspiración del fraile Arenas, ${ }^{34}$ paro también aparecieron voces contrarias. En ese momento Juan María Acevedo tenía 60 años. Era natural de Tlacolula pero residía en Miahuatlán donde era mayordomo en la hacienda de Santa Ana. Un día se emborrachó y acudió a una tienda para comprar más alcohol y un par de zapatos. Simeón Pulido, cajero del establecimiento, platicaba con otros individuos sobre la Independencia y el peligro que representaban algunos españoles como el fraile Arenas. Pulido estaba borracho cuando dijo "que él era liberal, que no podía ver [a] los Europeos, ni menos a los chaquetas". ${ }^{35}$ Acevedo escuchó tales palabras y replicó a Pulido "que él sí era chaqueta y que él por el rey moría". Agregó, además, que:

Yo no soy hablador amigo sino muy claro y por eso digo que doy la vida por el rey de España con cuyo gobierno me he criado por eso no defiendo esta nación que era gentil antes de su conquista y si por estas expresiones me han de matar, bien lo pueden hacer en esa plaza, en prueba de que amo al rey de España, vea usted este peso lo que tiene pintado y sepa $\mathrm{V}$. que tengo doscientos guardados en mi caja y que no tomo de esos de resplandor, sino los de mi Rey, jay mi Católico Rey!36

${ }^{31}$ Cab y May, "El águila...”, 273-293.

${ }^{32}$ Guardino, El tiempo..., 274-275.

${ }^{33}$ Citado en Plasencia, Independencia y nacionalismo..., 30. Véase también, Guardino, El tiempo..., 274.

${ }^{34}$ Pani, “De coyotes...", 355-374.

${ }^{35}$ El término "chaqueta" aludía al uniforme que empleaban algunas compañías realistas de la ciudad de México durante la guerra de Independencia. Moisés Guzmán Pérez, "Chaquetas, insurgentes y callejistas. Voces e imaginarios políticos en la independencia de México", en Las independencias hispanoamericanas, ed. de Véronique Hébrard y Geneviève Verdo (Madrid: Casa de Velázquez, 2013), 145.

36 "Año de 1827. Criminal sumaria contra Juan María Acevedo mayordomo de la Hacienda de Santa Ana por injurias a las autoridades legalmente constituidas”, cCJo, Juzgado de Primero de Distrito, exp. 88, f. 1-100. 
La discusión se volvió un diálogo de ebrios. Pulido recriminó a Acevedo y este último le contestó: "Aun le pruebo a V. más que esta nación era gentil antes de que se conquistara y a los Europeos debemos la religión por eso yo no soy traidor a ellos". El acusado decía con insistencia que "el moriría por los Gachupines y que a él no le gustaba este gobierno y que él había de decir lo que su corazón sentía aunque lo arcabucearan en medio de la plaza" y que "él era adicto al partido de Fernando VII y por él había de dar la vida aunque lo colgaran en el palo que está en medio de la plaza". Entre todas las expresiones de Acevedo sobresale la de " $i a y ~ m i$ Católico Rey!”. ¿Por qué lo hizo si México era un estado confesionario cuya religión oficial era el catolicismo, según la Constitución de 1824 ? Con todo, el creía que los liberales eran contrarios a Dios debido a la proliferación de grupos masones concebidos a menudo como "ateos" o "herejes". Además, Acevedo anhelaba el retorno de la monarquía para demostrar agradecimiento a los españoles que habían evangelizado a un pueblo que vivía en la idolatría, no conocía los avances científicos de Europa y había recibido de ellos la lengua española con la que se expresaba cotidianamente.

En la causa judicial Acevedo negó su adhesión a la Corona pero varios testigos confirmaron sus palabras y el juez falló en su contra, especialmente porque en sus pertenencias se encontró la moneda con el busto de Fernando VII. Los testimonios y las pruebas concordaron. La pena, sin embargo, fue suave porque se comprobó que el acusado estaba borracho cuando se expresó a favor de España. También lo ayudó mucho su edad avanzada y sólo se le condenó a pagar 50 pesos o realizar cuatro meses de obras públicas.

Otro caso de fernandismo tras el descubrimiento de la conjura de Arenas lo hizo Felipe Valdivieso quien tenía 25 años, estaba casado, ejercía el oficio de carnicero y era natural y residente de Juchitán. En la noche del 8 de septiembre de 1827 acudió a la tienda del español Carlos Castiñeiras para comprar aguardiente de caña. En estado etílico gritó "viva la España, viva el Rey y que muera la América con su gobierno y que hará arcabucear a todo este Ayuntamiento [de Juchitán]”. Estando preso dijo "viva España y que viva Fernando VII". Los testigos ratificaron la acusación y Valdivieso argumentó en su defensa que estaba ebrio. El juez lo encontró culpable y lo sentenció a servir ocho años en la marina. Sin embargo, Valdivieso apeló su sentencia ante la Suprema Corte de Justica que ordenó su libertad alegando que el tiempo sufrido en arresto era 
castigo suficiente. ${ }^{37}$ Las palabras de Acevedo y Valdivieso, además de apoyar el restablecimiento de la monarquía, representaban una postura pública que reprobaba la república y abogaba por un gobierno conocido que les había dado su fe, su lengua y su cultura.

El 20 de diciembre de 1827 el gobierno federal decretó la primera expulsión de españoles. En Oaxaca el coronel Santiago García la secundó y obligó al congreso local a crear su propia ley. Pronto algunos individuos apoyaron a los españoles. En ese año en Tehuantepec, Cristóbal Rodas fue apresado por "ebrio holgazán" y estando en el cepo dijo: "Vivan los Gachupines y mueran los criollos”. Los testigos, y él mismo, declararon que el imputado estaba ebrio cuando pronunció tales palabras, motivo por el cual no sufrió pena alguna y resultó liberado. ${ }^{38}$

¿Por qué Rodas reprobó la expulsión de los españoles? Sus palabras expresaban molestia porque la ley transgredía las bases del plan de Iguala que dieron independencia a México, y pese a que había sido derogada en 1824, significaba que los españoles que permanecieron en el país deberían ser considerados mexicanos. No debemos olvidar, además, la experiencia de la guerra de Independencia. Tehuantepec era un importante emporio comercial y productor de añil que sufrió, junto a Jamiltepec, los estragos de los saqueos insurgentes que mermaron la producción de añil y de textil. ${ }^{39}$ Para Rodas, la revolución había traído más miseria que beneficios, pues antes, durante y tras la Independencia, el ingreso de mercancías extranjeras más baratas que las nacionales (principalmente inglesas y estadounidenses) mermó todavía más la moribunda industria mexicana fuertemente golpeada por la guerra civil de $1810 .^{40}$

En 1829 el brigadier Barradas desembarcó en las arenas de Tamaulipas para reconquistar la antigua colonia. Las esperanzas de ser gobernados nuevamente por Fernando VII reaparecieron entre algunos mexicanos. En la ciudad de Oaxaca, José Carlos Rendón (casado, sombrerero y mayor de

37 “Año de 1827. Contra Felipe Valdivieso vecino del pueblo de Juchitán por haber dado el grito de 'Viva España' 'Viva el Rey' 'Muera la América con su gobierno'”, ccjo, Juzgado de Primero de Distrito, exp. 95, f. 1-56.

38 "Año de 1827. Sumaria averiguación hecha contra el Sr. Cristóbal Rodajo por faltas a las autoridades legalmente constituidas”, ccjo, Juzgado de Letras, exp. 93, f. 1-12.

${ }^{39}$ Arrioja, "Problemas...", 175.

${ }^{40}$ Sobre el impacto de textiles extranjeros en la industria mexicana, véase Ciro Cardozo, "Las industrias de transformación 1821-1880", en México en el siglo XIX (1821-1910) historia económica y de la estructura social, coord. de Ciro Cardozo (México: Nueva Imagen, 1982), 147-166. 
50 años) comenzó a beber aguardiente y pulque desde las 10:00, según su declaración. Esta información fue ratificada por otros testigos quienes lo vieron tambaleándose entre las 16:30 y 17:00 de la tarde. Rendón "daba voces de Viva Fernando VII", "Viva Carlos", "Viva España”, “Soy Fernando VII" y que "el era soldado del Rey". Además, dijo que "el sería el primero que derramaría hasta la última gota de su sangre por Fernando VII". Ante tales palabras un transeúnte le contestó con ironía "que él era Fernando Octavo". Dada su condición de dipsomanía, Rendón no fue juzgado como traidor sino como un borracho empedernido. ${ }^{41}$

El archivo judicial citado no permite conocer el pasado de Rendón pero sus palabras sugieren que fue un soldado realista durante la guerra de Independencia. ¿Por qué se expresó a favor de la Corona en un momento tan crítico como la invasión de Barradas? Probablemente observaba con nostalgia las utilidades que el conflicto de 1810 pudo proporcionarle como el botín. Juan Ortiz Escamilla señala que durante la guerra de Independencia el general Félix María Calleja obtuvo muchos bienes gracias a los saqueos y confiscaciones. ${ }^{42}$ Es probable que Rendón hubiera recaído en la misma práctica y que la emancipación interrumpió sus ganancias. Más importante aún, Rendón perdió los beneficios que su puesto militar le confirió (estatus social y paga). Se sugiere, entonces, que Rendón anhelaba el status quo que la Independencia había destruido y que tantas utilidades económicas le habían otorgado bajo la Corona y que, con la invasión de Barradas, esperaba recuperar.

Los casos anteriores develan ciertos elementos en conjunto. Las palabras subversivas recayeron sólo en los hombres, pues no existe registro alguno de una mujer vociferando a favor de Fernando VII. Todos los acusados, salvo Rodes que no se supo su edad, vivieron la experiencia de la guerra de Independencia así como la transición a imperio y después a república. Acevedo tenía 60 años, Rendón 50 y Valdivieso 25. La media de edad fue de 45 años. Esto indica, por lo tanto, que la república resultaba para ellos un experimento fallido que hacía añorar los días de la monarquía.

41 "Año de 1829. Criminal instruida contra José Carlos Rendón, por haber dicho expresiones subversivas y alarmantes contra el supremo gobierno de la Nación”, Archivo General del Estado de Oaxaca (en adelante AGEo), Milicia, Tribunal Militar, Juicios, caja 438, exp. 1, f. 1-9.

42 Juan Ortiz Escamilla, Calleja. Guerra, botín y fortuna (Xalapa; Zamora: Universidad Veracruzana/El Colegio de Michoacán, 2017), 71-253. 
Todos los acusados, además, estaban borrachos cuando se pronunciaron a favor de la Corona. ¿Por qué no lo hicieron sobrios? Porque estaban conscientes de que transgredían las nuevas leyes. El licor, sin embargo, y como apunta William Taylor para su clásico estudio colonial, desinhibe a las personas provocando que se expresen sin tapujos o que realicen comportamientos reprobables. ${ }^{43}$ El problema de la ebriedad persistió durante la Colonia, época en que se toleraba con cierta holgura. ${ }^{44}$ Tras la Independencia el ayuntamiento de Oaxaca trató de modificar su expendio y en 1822 intentó "contener los excesos que causan los abusos en la venta de licores”. El bando condenaba la expedición de pulque en las casas privadas así como en las vías públicas. El decreto, además, "prohíbe también que nadie beba en las vinaterías, pues el comprador deberá llevar una vasija en que conducir el vino o aguardiente, evitando de este modo la reunión de ebrios en las tiendas". ${ }^{45}$ Estas medidas resultaron insuficientes, pues los borrachos continuaban desfilando en las calles y dos años después el ayuntamiento capitalino expidió un nuevo bando para "que no se venda pulque de las tres de la tarde en adelante", ${ }^{46}$ lo que sugiere que atardecer y alcoholismo eran la combinación perfecta para pronunciar palabras sediciosas y delinquir. ${ }^{47}$

Jaime Rodríguez y Gabriel Torres Puga sostienen que en los lugares de esparcimiento como cafés, billares y casas donde se practicaban las tertulias, las ideas convergieron y circulaban las noticias y opiniones impresas en la prensa durante la segunda mitad del siglo XviII. ${ }^{48}$ Para el siglo siguiente,

${ }^{43}$ William B. Taylor, Embriaguez, homicidio y rebelión en las poblaciones coloniales mexicanas (México: Fondo de Cultura Económica, 1987), 99.

${ }^{44}$ Guardino, El tiempo..., 157.

${ }^{45}$ Archivo General de la Nación (en adelante AGN), Gobernación, caja 55, exp. 13, f. 1.

${ }^{46}$ Archivo Histórico Municipal de la Ciudad de Oaxaca "Manuel R. Palacios" (en adelante Анмсо), Libro de Actas de Cabildo, libro 6, f. 217. Los libros de Actas de Cabildo están foliados tres veces. Para mi estudio tomé en consideración la foliación hecha con lápiz.

${ }^{47}$ Alcohol y violencia iban de la mano. En las periferias de la ciudad de Oaxaca "el día 20 del corriente [20 de diciembre de 1823] se le avisa al sargento Pedro Calderón comandante de dicha ronda, que en el camino de Xoxo[cotlán] había una reunión de hombres ebrios que con cuchillos y piedras se estaban asesinando". Aнmco, Libro de Actas de Cabildo, libro. 6, f. 38.

${ }^{48}$ Jaime E. Rodríguez, Nosotros somos ahora los verdaderos españoles, v. I (México: El Colegio de Michoacán/Instituto de Investigaciones Dr. José María Luis Mora, 2012), 47-48; y Gabriel Torres Puga, Opinión pública y censura en Nueva España. Indicios de un silencio insoportable 1767-1794 (México: El Colegio de México, 2010), 311. Otros puntos de reunión para intercambiar ideas fueron la plaza de toros y el espacio para el juego de pelota aunque 
Clementina Díaz de Ovando caracterizó a los cafés como centros de disidencia y de desafío organizado contra la autoridad hegemónica. ${ }^{49}$ Las pulquerías, cantinas, tabernas e incluso las tiendas del México independiente también fueron espacios donde se expresaron ideas y sentimientos contrarios al régimen imperante pero, a diferencia de los cafés y de las de tertulias, el caso oaxaqueño sugiere que las ideas fueron desorganizadas y carentes de adeptos porque la afluencia de personas se debía más bien a la búsqueda de juegos, prostitutas y entretenimiento.

Otro elemento es el perfil del individuo que acudió a los lugares de sociabilidad. Mientras los cafés y tertulias se nutrieron de personas letradas quienes discutían las noticas del mundo, los avances científicos y las corrientes filosóficas, económicas y teológicas, los lugares de recreación con alcohol, según los datos arrojados en la presente investigación, atraían a los sectores populares representados por vagos (un holgazán), trabajadores de hacienda (un mayordomo), artesanos (un sombrerero) y trabajadores de diversos oficios (un carnicero). Lo anterior sugiere que el índice de escolaridad y preparación académica (incluso de alfabetismo), incidió negativamente en la capacidad organizativa de los descontentos fernandistas quienes sólo manifestaban su molestia pero no actuaron.

¿Qué papel tuvieron los individuos que denunciaron a los infidentes? Considero que el pueblo mexicano combatió en dos frentes de guerra, uno externo (militar) y otro interno (civil). El primero refiere a las tropas que asediaron San Juan de Ulúa hasta 1825 y a aquellos que combatieron a Barradas en 1829. El segundo engloba a los mexicanos que denunciaron a los afectos a la Corona y quienes colocaron la primera piedra de la represión gubernamental, pues todo proceso judicial o militar comienza con una denuncia. Con otras palabras, los coterráneos que delataron y testificaron contra los infidentes fungieron como vigilantes y protectores de la Independencia y de la república en un contexto de conflicto internacional y de disidencia interna.

Ahora bien, con la derrota de Barradas el apoyo verbal hacia Fernando VII decayó y dio paso al material. En 1831, Francisco Morales, alcalde 30. provisional de la ciudad de Oaxaca, fue solicitado ante el gobernador del estado “y hallándome presente ante su señoría me entregó un niño de tierna

en estos lugares fluían tanto los sectores populares como las élites. Torres Puga, Opinión pública..., 312.

${ }^{49}$ Clementina Díaz y de Ovando, Los cafés en México en el siglo XIX (México: Universidad Nacional Autónoma de México, 2017), 13. 
edad [...] un listón que tiene un rotulón impreso y un retrato de Fernando VII en el cual se lee 'por Fernando VII vencer o morir (sic)' ". El alcalde 3o. interrogó al infante cuyo nombre era Manuel María Cayetano, de once años, nacido en Huitzo y residente en la capital del estado. Cayetano confesó que el listón "lo halló en el muladar del callejón de la Soledad" y que su tía se lo había quitado. Posteriormente un soldado del ejército mexicano lo presentó ante las autoridades militares de la ciudad. Pese a su corta edad, se sabe que el niño fue detenido en la cárcel y puesto a disposición del alcalde $30 .{ }^{50}$

Se ignora la resolución de la diligencia contra el infante Cayetano. Tampoco se averiguó quién realizaba tales distintivos. Era común el uso de objetos con inscripciones de Fernando VII. En 1829 y tras la invasión de Barradas, Francisca del Rosario Fernández hacía obleas decoradas con la frase de "Viva Fernando Séptimo". Ella y Juan Nepomuceno Rivas (vendedor) fueron amonestados para no volver a comerciar con tales dulces y el molde con que se hacían las obleas resultó modificado. ${ }^{51}$ En ambos casos se aprecia una política nacional destinada a borrar todo vestigio material que recordara el pasado colonial y el culto a la monarquía. Tales acciones estaban encaminadas a crear ciudadanos y a combatir la pleitesía para un rey que, ante la intransigencia de no reconocer la Independencia de México, se había convertido en el mayor enemigo del país y en el representante político con la única nación que se estaba en guerra.

La muerte de Fernando VII en 1833, así como el reconocimiento de la Independencia de México por parte de la antigua metrópoli tres años después, menguó las esperanzas de algunos miembros de las clases populares del retorno de un rey Borbón. En resumen, la adhesión hacia la Corona fue una nostalgia por la Colonia y sus instituciones, una manifestación de muchos borrachos por una época que consideraban mejor o en la cual habían obtenido beneficios económicos como soldados del rey. Otros dipsómanos, en cambio, expresaban agradecimiento por aquellos quienes les habían dado su fe y, al mismo tiempo, velado por la salvación de sus almas salvándolos de una eternidad en el averno.

50 "Año de 1831. Información Pedida por el Señor Gobernador del Centro, en averiguación de un niño...”, AGEo, Criminal, Diligencias, caja 542, exp. 25, s/f.

51 "Año de 1829. Criminal contra Francisca del Rosario Fernández y D. Juan Nepomuceno Rivas: la primera fabricante de obleas que tienen la inscripción de Viva Fernando Séptimo y el segundo vendedor de ellas”, ccјo, Juzgado Primero de Distrito, exp. 173, f. 1-8. 
Un estudio de caso

En el presente apartado realizo un estudio particular de fernandismo, el cual posee dos expedientes judiciales muy extensos y completos. También representa la única ejecución y el excepcional caso de un infidente que se expresó a favor de la Corona estando sobrio. Con todo, intentó salvar su vida alegando ebriedad y luego locura. El 26 de noviembre de 1826, entre 04:30 y 05:00, el teniente Navor María Carrión escuchó "una voz de viva Fernando y que muero por mi Rey". La proclama venía de una de las celdas del cuartel de Jamiltepec, y Carrión se presentó a indagar la causa del escándalo. Ya había algunos soldados sondeando la escena. Como el ruido no cesaba, Cipriano Rosete, el sargento de la guardia principal, acudió a la cárcel para aplacar al que vociferaba tales palabras. El sargento, al abrir la puerta de la jaula, "recibe dos garrotazos en la frente que le abrieron dos incisiones”. El atacante era Ursulino Guzmán quien después de golpear al sargento "se puso en precipitada fuga a quien siguió la tropa a su alcance y habiéndolo conseguido fue conducido a la cárcel nacional". Gracias a la intervención de los soldados, quienes capturaron al agresor, presentamos el análisis de la causa castrense contra Guzmán. ${ }^{52}$

La primera declaración fue la de Rosete, quien tenía 20 años y era Sargento 2o. de la 1a. Compañía del Batallón Activo Guardacosta de Jamiltepec. Su testimonio resulta vital porque él era el encargado inmediato de los reos, presenció las palabras sediciosas de Guzmán y también sufrió su agresión física. El sargento dijo que después de haber escuchado el toque de diana, percibió mucho ruido proveniente de la cárcel. Preguntó entonces al cabo Miguel Clavel quién era el responsable del alboroto y éste le contestó "que era uno de los arrestados que desde antes estaba alterando [la tranquilidad] para que se le permitiese el salir a mear". Como Guzmán continuaba haciendo escándalo, el sargento Rosete envió al cabo Gaspar Ramírez y a dos soldados más "a ver qué cosa era y que [se] impusiese silencio". Con todo, el mismo Rosete se presentó en la cárcel:

Y que al llegar a la primera puerta del boquete halló allí al cabo y dos soldados que había despachado y con ellos al subteniente Don Navor Carrión y oyó que el referido arrestado cuyo nombre ignora, estaba diciendo voz en grito por la parte de

52 A menos que se diga lo contrario, toda la información fue tomada de "Año de 1826", Ageo, Milicia, Tribunal Militar, Diligencias, caja 430, exp. 12, f. 1-12. 
dentro viva Fernando VII, yo por Fernando VII he de dar la vida: me cago en la Nación. Entonces el que declara empujó la puerta para entrar pero el reo se la volvió a cerrar, y habiendo de nuevo empujado con más fuerza la abrió y entró, mas el agresor que se encubrió con la hoja de la misma puerta lo recibió dándole un palo en la frente, del que no pudo precaverse el declarante, y siguió dándole de palos de que se escudó con su fusil que resultó despedazada la caja; y habiendo entrado en su socorro el cabo, también lo recibió del mismo modo y en seguida se puso en fuga atropellando a los dos soldados que estaban en la puerta en cuya vista el declarante echó sobre él la guardia para su persecución la que persiguió toda la tropa franca que se hallaba formada enfrente del cuartel y se alcanzó por el soldado Santos Escobar a distancia de ciento cincuenta varas hacia el monte sirviendo de ocasión para ello el haberse caído y se trajo de nuevo seguro a la cárcel y a su llegada intentó otra vez fugarse..$^{53}$

En seguida testificó José María Reynoso, curandero del pueblo. Se le preguntó sobre las heridas que Guzmán infirió al sargento Rosete. Según su testimonio, el sargento poseía "dos heridas contusas". Una "enfrente sobre la ceja y la otra en el nacimiento de la nariz". El tamaño de la primera era de una pulgada de largo y una línea de ancho. La segunda de "media línea de longitud y dos de latitud". La primera podía ser peligrosa porque "puede haberse interesado el cráneo". El siguiente testimonio correspondió a Amaro Meza, quien tenía 26 años y era capitán de la 6a. Compañía del Batallón activo de Jamiltepec. No atestiguó el suceso ni aportó nada a la causa.

El siguiente testigo fue Navor María Carrión, quien tenía 30 años y era subteniente de la 6a. Compañía del Batallón de Jamiltepec. Acudió a la cárcel porque desde ese lugar salían palabras inteligibles y halló a dos soldados y a un cabo que pretendían ingresar a una jaula. Carrión ahora pudo entender con claridad las palabras de Guzmán, quien decía "yo muero por mi Dios y por mi Rey, viva España y viva mi Fernando 7o. cuyas expresiones repetía incesantemente y a gritos, amenazando a los guardias diciendo entren Carajos y volvía a repetir su misma proclamación (sic)". El resto de la declaración de Carrión coincide con la del sargento Rosete.

El siguiente testimonio correspondió a Gaspar Ramírez, quien tenía 32 años y era cabo 2o. de la 6a. Compañía del Batallón Activo de Jamiltepec. Estando de guardia, lo llamó el soldado José Clavel, quien era el centinela de la cárcel y le reportó que un reo intentaba fugarse de la prisión. Ramírez ordenó que de efectuarse tal tentativa "le calara bayoneta" y se retiró, pero

${ }^{53}$ El subrayado proviene del mismo documento histórico. 
como Guzmán continuaba con sus expresiones, Ramírez acudió con dos soldados "y ya entonces oyó que el reo estaba diciendo que él con seis hombres de su opinión se había de cagar en toda la guarnición y que por Dios y por su Rey había de morir, Viva España y viva mi rey Fernando 7o, me cago en la Nación; repitiendo estas expresiones muchas veces". Acto seguido llegó el sargento Rosete, quien abrió la puerta y recibió dos heridas en la frente. Ramírez, al observar esto auxilió al sargento, "recibiendo un garrotazo en el píe izquierdo". Guzmán huyó mientras gritaba "Viva Fernando 7o. y viva España". Tras ser capturado y puesto en el cepo "todavía repitió que por su Rey Fernando 7o. había de morir y que con un machete en las manos no era capaz que lo hubieran cojido".

Finalmente, Guzmán compareció. La primera pregunta giró en torno a su vida. Dijo ser natural y vecino de Tlacamama y tener 50 años. Omitió señalar su estado civil (en una causa militar previa dijo estar casado) pero confesó ser "paisano sin empleo alguno" (en la primera causa militar dijo ser labrador). La segunda pregunta consistió en explicar la razón de su prisión. Pudiera parecer una pregunta innecesaria, pues las autoridades sabían perfectamente el motivo por el cual interrogaban al acusado. Sin embargo, este cuestionamiento era una vieja trampa colonial para saber si el imputado había cometido otro crimen que las autoridades ignoraban. Guzmán "dijo que porque lo querían arcabucear y no se quiso confesar". El acusado mintió. De acuerdo con una causa militar previa iniciada el 18 de noviembre de 1826, Guzmán había sido arrestado por decir que un individuo (Manuel Herrera) vociferaba "hay aquí más chaquetas Criollos que Europeos". 54

La tercera cuestión consistió en saber dónde estaba Guzmán a las cinco de la mañana. La respuesta era obvia, en la cárcel. La cuarta pregunta pretendía indagar qué dijo Guzmán a esa hora. El acusado respondió que "las expresiones que vertió fueron las de viva la Independencia y Fernando $7^{\circ}$ ". Continuó diciendo "que éste fue su delito y que lo hubieran matado y muerto se hubiera quedado si le hubieran hecho fuego". La defensa de Guzmán parecía contradictoria a simple vista. Por un lado defendió la Independencia y por otro lado al monarca de España. Sin embargo, implícitamente invocó el tratado de Iguala el que otorgaba la soberanía a México pero en manos de Fernando VII o de algún miembro

54 “Año 1826. Sumaria criminal contra Manuel Herrera y Ursino Guzmán de Tlacomama por lo que expresa”, AGEo, Milicia, Tribunal Militar, Diligencias, caja 430, exp. 2, f. 1-10. 
de la Corona. Su intención era suavizar lo que verdaderamente había dicho: "Viva España y viva mi rey Fernando 7o.", pues él relacionó la mancuerna de España como metrópoli y Fernando VII como la cabeza de los reinos americano y europeo.

Guzmán recurrió en su declaración al tratado de Iguala porque ninguno de los soldados quienes testificaron señaló que el acusado hubiera dicho "Viva la Independencia”. Todo lo contrario. Guzmán, según estos testimonios, expresó una y otra vez adhesión hacia España incluso cuando estaba en el cepo. Esto sugiere que la confesión del reo estaba delimitada por el miedo y las penas que podía sufrir como castigo. Guardino, en su estudio sobre los tumultos en el distrito de Villa Alta, Oaxaca, señala que los interrogatorios "se hicieron en una atmósfera de temor a las penas que pudiera imponer el Estado". ${ }^{55}$ En este sentido, Guzmán omitió que hubiera dicho "me cago en la nación” y "que él con seis hombres de su opinión se había de cagar en toda la guarnición" de Jamiltepec. También soslayó que hubiera golpeado a varios soldados.

La quinta pregunta consistió en saber por qué intentó huir. Guzmán "dijo que [se] fugó porque lo querían fusilar y él quería confesarse: que esto ya la había escrito el Sr. comandante y lo había perdonado". El miedo a perder la vida explica su huida de la cárcel, mas no por qué se expresó a favor de Fernando VII. Guzmán vivió la época colonial en paz, en guerra y en su término. Guzmán probablemente no la pasó del todo bien durante la Colonia pero al menos en esa época quizás no pisó una celda, como sí lo sufriría en la independencia. Lo que sí fue un hecho es que las incursiones insurgentes destruyeron la economía de Jamiltepec y que no se había recuperado tras la Independencia. Esto sugiere que la emancipación le había traído más desgracias que beneficios, si consideramos que la economía había decaído y que estar en prisión significaba enfrentar hambre, frío, convivencia con alimañas y maltrato de los carceleros.

La sexta pregunta pretendía saber por qué golpeó al sargento Rosete. Guzmán contestó que el sargento lo amenazó con fusilarlo. La séptima cuestión en realidad tuvo el carácter de un imperativo: "Confiese como sin temor a las leyes y sin respeto alguno a las Armas Nacionales ha proclamado esta mañana al Rey de España con ultraje de toda la Nación

55 Peter Guardino, “'El carácter tumultuoso de esta gente'. Los tumultos y la legitimidad en los pueblos oaxaqueños, 1768-1853”, en Poder y legitimidad en México en el siglo XIX, coord. de Brian F. Connaughton (México: Universidad Autónoma Metropolitana-Iztapalapa/Miguel Ángel Porrúa, 2003), 183. 
Mexicana y de esta guarnición”. Guzmán ahora fue más cauteloso al responder e incluso implícitamente se retractó: "Que no dijo más sino que viva la Independencia [y] nuestro Fernando: tonteras que ocasionaron el castigo (sic)".

La octava pregunta sondeó al reo sobre la gravedad de proclamarse a favor de un reino extranjero y de golpear a los soldados. Guzmán respondió con la clásica contestación de un prisionero en apuros: "que lo hizo estando borracho", siendo esto una mentira porque el acusado fue arrestado en estado de sobriedad. Pero el confesante tenía, además, otro as bajo la manga. Cuando los interrogadores estaban a punto de concluir la diligencia, Guzmán la interrumpió "diciendo que había más chaquetas criollos que Gachupines (sic)”. Su expresión no tenía relación con esta indagatoria, sino con la primera, pareciendo, más bien, un recurso del reo para confundir a los interrogantes y así postergar su condena.

Las autoridades mordieron el anzuelo y le preguntaron ¿quiénes eran los “chaquetas criollos”? Guzmán contestó que Leonardo Jiménez, Felipe Reyes y otro individuo que iban a fusilar esa mañana. Tras el supuesto desvarío de Guzmán, como fue entendido por los jueces, se suspendió la causa y se procedió "al reconocimiento de su legítimo estado de juicio por medio del práctico y [de] dos testigos”. El facultativo concluyó que "no estaba enteramente loco pero si se haya demente pero que da esperanzas de volver a su juicio por medio de las medicinas". La causa reinició y los testigos volvieron a testificar para saber si Guzmán sufría algún trastorno mental. Todos dijeron que no, que él estaba "en su sano juicio". Julián González Meza, comandante graduado del Batallón del Ejército y primer ayudante del Regimiento Activo Guardacostas de Jamiltepec y dictaminador fiscal de la causa, declaró culpable a Guzmán:

Primero por haber proclamado a España y a su execrable Rey con allanamiento de la Soberanía de la Nación en la expresión obscena de cagarse en ella; en el segundo por haberlo dicho a gritos en presencia de un destacamento de la guardia, a oídas con al frente de toda la Tropa formada [...] y por último en el de alevosía por el modo traidor con que hirió al sargento esperándolo encubierto tras la puerta; y aunque este reo al reproducir su confesión aparece como delirante y como demente, lo cual hizo creer al práctico curandero y dos testigos (y dos testigos), no puedo persuadirme de que sea efectiva tal denuncia, tanto porque está justificado que al cometer los crímenes estaba en su juicio, como porque de aquel momento en el que se le tomó la confesión sólo mediaron seis horas, debiendo creerse que este hombre desnaturalizado, conociendo la enormidad de 
sus crímenes como lo confiesa a pesar suyo, y mirando que no puede librarse del castigo que merece, se valió del recurso de fingirse loco (sic).

El comandante González ordenó “que todo el rigor de la Ley” recayera sobre el acusado y lo sentenció a muerte. Un escribano, entonces, se dirigió a la capilla donde el reo, ya confesado con un clérigo, esperaba la resolución de su causa. El escribano le solicitó hincarse para leerla. Eran las 15:00, y 30 minutos después el condenado se dirigía al paredón. Ahí se le colocó de rodillas y de espaldas mientras se leían sus crímenes. El orador concluyó y poco después una descarga interrumpió el silencio. El cuerpo cayó inerte mientras salpicaba el suelo con sangre. El escuadrón de fusilamiento desfiló frente al cadáver que fue enterrado en la parroquia de Jamiltepec.

¿Qué explica el fernandismo de Guzmán? La experiencia de la guerra de Independencia y la visión mesiánica que todavía se tenía de Fernando VII. La localidad de Jamiltepec fue invadida por los insurgentes pero fue más fácil conquistarla que pacificarla. En 1813, tras la salida del cura Morelos de la intendencia de Oaxaca, los "negros”, como el cura Morelos los llamaba dada su ascendencia africana, se levantaron en armas. Después de derrotarlos e integrarlos a las banderas insurgentes, nuevamente aparecieron brotes de fidelidad hacia el realismo, provocando el enojo del cura Morelos:

Ahora suscitan la rebelión más impolítica e indigna que cabe en los ingratos; expresan sus sentimientos sediciosos en sus papeles, que circulan en toda la costa, nos tienen entretenida mucha parte de la tropa, que podía estar sirviendo en aumentar el país de la libertad; ha dejado a Oaxaca en un estado de debilidad, que se hace algo dudosa su defensa, y últimamente han enervado todos los movimientos del ejército. ${ }^{56}$

El testimonio del cura Morelos revela que parte de la población de Jamiltepec se mantuvo leal al realismo siendo un importante núcleo contrarrevolucionario aun sin la presencia de las tropas del rey. Sus actividades contrainsurgentes como el levantamiento armado o la propaganda escrita socavaron la autoridad rebelde. Si bien tales acciones no lograron expulsar

56 "Carta de Morelos a Bustamante sobre la necesidad de reprimir a rebeldes de Jamiltepec”, en Morelos Antología documental, comp. de Carlos Herrejón Peredo (México, Secretaría de Educación Pública, 1985), 137. 
a las huestes de Morelos, tuvieron cierto éxito porque impidieron la pacificación del territorio y distrajeron a los rebeldes evitando así que el movimiento se expandiera a otras partes del virreinato. Guzmán fue testigo de esta fidelidad realista en Jamiltepec y su fernandismo era una consecuencia de la guerra de Independencia, pues tal localidad se mantuvo como un reducto de la Corona pese a su caída.

Por otra parte, Eric Van Young señala que Fernando VII estaba relacionado con "una figura ferozmente reaccionaria". ${ }^{57} \mathrm{Su}$ absolutismo se patentizó en 1814 cuando retornó de su cautiverio, disolvió las cortes de Cádiz y reestableció la Inquisición. Sin embargo, en 1820 se le obligó a firmar una constitución que resultó efímera dada la invasión francesa de 1823 que restauró el absolutismo. Los mexicanos adictos a Fernando VII, entonces, imitaban el comportamiento de la Corona pero, además, expresaban el deseo del advenimiento de un mesías. ${ }^{58}$ Los últimos años de la Nueva España fueron convulsivos. Hambre (crisis del maíz), guerra civil, aumento de tributos, epidemias (fiebres misteriosas), saqueos, pérdidas económicas y muerte crearon un ambiente apocalíptico. Estos problemas no terminaron con la consumación de la Independencia. La epidemia de sarampión de 1825 y el cólera de 1833 sustituyó a las fiebres misteriosas. Los saqueos y la muerte continuaron apareciendo en los caminos principales gracias a las acciones de antiguos jefes insurgentes quienes encontraron en el bandidaje una nueva forma de subsistir. La economía, por lo demás, parecía resquebrajarse dado el ingreso de productos extranjeros más baratos que inundaron el mercado nacional a través del contrabando. Los problemas de la colonia continuaban y en algunos casos se agravaban. Para los individuos descontentos con el nuevo gobierno mexicano, la llegada de un mesías se hizo indispensable porque significaba la solución de todos los problemas que la nación enfrentaba. Ese salvador estuvo personificado en Fernando VII.

57 Young, La otra rebelión..., 800.

${ }^{58}$ Rey y mesías iban de la mano en el imaginario español y novohispano. Fernando el Católico, por ejemplo, poseía todas las virtudes del hombre pero, además, la representación humana de un salvador. Teresa Jiménez Calvente, "Fernando el Católico. Un héroe épico con vocación mesiánica", en La imagen de Fernando el Católico en la historia, la literatura y el arte, coord. de Aurora Egido y José Enrique Laplana Gil (Zaragoza: Institución Fernando el Católico, 2014), 131-170. 


\section{Consideraciones finales}

La mayoría de los casos expuestos de fernandismo popular aparecieron en la época de mayor conflictividad entre españoles y mexicanos, es decir, entre 1823 y 1829. La descubierta conspiración del fraile Arenas, la expulsión de los españoles y el intento fallido de reconquista de Barradas aumentaron, en algunos mexicanos, el deseo del restablecimiento del gobierno de Fernando VII. En este sentido, los sucesos internacionales entre la monarquía española y la república mexicana hicieron que el realismo sobreviviera a la Independencia. Esto, a su vez, alimentó las manifestaciones monarquistas y republicanas de los oaxaqueños. Unos se manifestaron a favor del antiguo rey, pero otros lo detestaban. Si bien los segundos denunciaron y testificaron contra los adictos a la Corona, los primeros invocaron, al menos estando ebrios, al mesías que se creía terminaría con los males que padecía la República.

La ciudad de Oaxaca se convirtió en un bastión del gobierno oficial (virreinal primero, imperial después y republicano finalmente). Esto sugiere que las élites políticas supieron adaptarse a los nuevos sistemas políticos, pero también que los defendieron. Otros puntos del estado replicaron la postura de la capital republicana vigilando a los sospechosos de monarquismo. En el estado de Oaxaca se intentó exterminar la infidencia a través de penas económicas o de la purificación de sus palabras a través del trabajo en obras públicas. Las autoridades fueron, en términos generales, bastante afables en las condenas impuestas. Antes que dictar castigos ejemplares como el escarmiento, la confiscación de bienes o la ejecución que fueron tan comunes durante la guerra de Independencia, se buscó la reconciliación. La única pena de muerte que se realizó fue contra un individuo que atacó física y verbalmente a los soldados mexicanos acantonados en Jamiltepec.

La postura de las clases populares resulta compleja dadas las múltiples transiciones políticas. Algunos adoptaron el republicanismo, pero otros quedaron anclados en el antiguo régimen convencidos de que era la mejor forma de gobierno, ya que encontraron muy decepcionante el sistema republicano. Había un Dios en el cielo pero faltaba un rey en la tierra que fue recordado, en momentos de algarabía y borrachez, como el mesías que destruiría el liberalismo. Este sentimiento fue marchitándose con las derrotas monarquistas (el fracaso de Arenas y Barradas) hasta sucumbir junto al "El Deseado" en 1833. 


\section{FUENTES CONSULTALDAS}

Archivos

Archivo General de la Nación (AGN), Ciudad de México, Gobernación, Sin Sección. Archivo General del Estado de Oaxaca (AGEo), Oaxaca de Juárez, Oaxaca, Justicia, Milicia.

Archivo Histórico Municipal de la Ciudad de Oaxaca "Manuel R. Palacios" (AнмCo), Oaxaca de Juárez, Oaxaca, Libro de Actas de Cabildo.

Casa de la Cultura Jurídica en Oaxaca (сслo), Oaxaca de Juárez, Oaxaca, Juzgado de Letras, Juzgado Primero de Distrito.

Fuentes documentales

Cos, José María. Escritos políticos. Selección, introducción y notas de Ernesto Lemoine Villicaña. México: Universidad Nacional Autónoma de México, 1967.

Herrejón Peredo, Carlos, comp. Morelos. Antología documental. México: Secretaría de Educación Pública, 1985.

\section{Bibliografía}

Arrioja Díaz Viruell, Luis Alberto. "Problemas y coyunturas internas. Una visión del sexenio absolutista desde Villa Alta (Oaxaca)." En La guerra de Independencia en Oaxaca. Nuevas perspectivas. Coord. de Carlos Sánchez Silva, 171-196. Oaxaca: Universidad Autónoma Benito Juárez de Oaxaca/Comisión Permanente de Cultura de la LXI Legislatura del H. Congreso del Estado de Oaxaca/ Universidad Autónoma Metropolitana, 2010.

Arrioja Díaz Viruell, Luis Alberto y Carlos Sánchez Silva. "Melchor Álvarez Thomas, comandante general de la intendencia de Oaxaca, 1813-1818." En Los comandantes realistas y la guerra de Independencia. Coord. de Jaime Olveda, 219-252. Zapopan: El Colegio de Jalisco, 2010.

Ávila, Alfredo y Gabriel Torres Puga. "Retóricas de la xenofobia, franceses y gachupines en el discurso político y religioso de Nueva España (1760-1821).” 20/10 Memoria de las Revoluciones en México, n. 2 (septiembre-noviembre 2008): 36-43. Bernal Ruiz, Gabriela. "Se oyen voces. Rumor y miedo en la ciudad de San Luis Potosí, 1808-1811." En Entre rumores, ejércitos rebeldes, ansiedad impresa y representaciones épicas. Coord. de Moisés Gámez, 17-40. San Luis Potosí: El 
Colegio de San Luis/LIX Legislatura del H. Congreso del Estado de San Luis Potosí/Secretaría de Cultura del Gobierno del Estado de San Luis Potosí, 2010. Birrichaga Gardida, Diana. "Facciones y movilización electoral en Texcoco, 18201828." En Campañas, agitación y clubes electorales. Organización y movilización del voto en el largo siglo XIX mexicano. Coord. de Fausta Gantús y Alicia Salmerón, 141-184. México: Instituto Nacional de Estudios Históricos de las Revoluciones de México/Instituto de Investigaciones Dr. José María Luis Mora, 2019.

Cab Pérez, Fernando Jesús y Ángel Omar May González. "El águila contra el león. Construcción del discurso antihispanista y republicano en la prensa campechana (1824-1831).” Signos Históricos, v. 22, n. 43 (enero-junio 2020): 254-299. Cardozo, Ciro. "Las industrias de transformación 1821-1880.” En México en el siglo XIX (1821-1910) historia económica y de la estructura social. Coord. de Ciro Cardozo, 147-166. México: Nueva Imagen, 1982.

Castillo, Andrés del. “Acapulco, presidio de infidentes, 1810-1821.” En La Independencia en el sur de México. Coord. de Ana Carolina Ibarra, 153-192. México: Universidad Nacional Autónoma de México, Instituto de Investigaciones Históricas/Fideicomiso Felipe Teixidor y Monserrat Alfau de Teixidor, 2017.

Dalton, Margarita. Breve historia de Oaxaca. México: Fondo de Cultura Económica/ El Colegio de México/Fideicomiso Historia de las Américas, 2004.

Díaz y de Ovando, Clementina. Los cafés en México en el siglo XIx. México: Universidad Nacional Autónoma de México, 2017.

Esparza, Manuel. "La Iglesia de Oaxaca en tiempo de la Independencia. El obispo Bergosa y Jordán.” En La Guerra de Independencia en Oaxaca. Nuevas perspectivas. Coord. de Carlos Sánchez Silva, 39-62. Oaxaca: Universidad Autónoma Benito Juárez de Oaxaca/Comisión Permanente de Cultura de la LXI Legislatura del H. Congreso del Estado de Oaxaca/Universidad Autónoma Metropolitana, 2010.

Falcón, Romana. Las rasgaduras de la descolonización. Españoles y mexicanos a mediados del siglo XIX. México: El Colegio de México, 1996.

Flores Caballero, Romeo. Revolución y contrarrevolución en la Independencia de México, 1767-1867. México: Océano, 2009.

Gamboa Ojeda, Leticia y Emilio Maceda. "La expulsión de los españoles en Puebla y el perfil de los exceptuados, 1827-1828." Revista de Indias, v. LXIII, n. 228 (2003): 375-394. https://doi.org/10.3989/revindias.2003.i228.443.

González Leyva, Alejandra. "Las fortificaciones de Yanhuitlán durante la guerra de Independencia.” En La Guerra de Independencia en Oaxaca. Nuevas perspectivas. Coord. de Carlos Sánchez Silva, 137-148. Oaxaca: Universidad Autónoma Benito Juárez de Oaxaca/Comisión Permanente de Cultura de la LXI Legislatura del H. Congreso del Estado de Oaxaca/Universidad Autónoma Metropolitana, 2010. 
Guardino, Peter. El tiempo de la libertad. La cultura política popular en Oaxaca, 17501850. Oaxaca: Universidad Autónoma Benito Juárez de Oaxaca/Universidad Autónoma Metropolitana-Iztapalapa/El Colegio de San Luis/El Colegio de Michoacán/Congreso del Estado de Oaxaca, 2009.

Guardino, Peter. “'El carácter tumultuoso de esta gente’. Los tumultos y la legitimidad en los pueblos oaxaqueños, 1768-1853." Poder y legitimidad en México en el siglo XIX. Coord. de Brian F. Connaughton, 181-208. México: Universidad Autónoma Metropolitana-Iztapalapa/Miguel Ángel Porrúa, 2003.

Guzmán Pérez, Moisés. "Chaquetas, insurgentes y callejistas. Voces e imaginarios políticos en la independencia de México." En Las independencias hispanoamericanas. Ed. de Véronique Hébrard y Geneviève Verdo, 135-150. Madrid: Casa de Velázquez, 2013.

Hamnett, Brian R. Revolución y contrarrevolución en México y el Perú (liberalismo, realeza y separatismo 1800-1824). México: Fondo de Cultura Económica, 1978. Ibarra, Ana Carolina. “La experiencia insurgente en Oaxaca.” En La guerra de Independencia en Oaxaca. Nuevas perspectivas. Coord. de Carlos Sánchez Silva, 1718. Oaxaca: Universidad Autónoma Benito Juárez de Oaxaca/Comisión Permanente de Cultura de la LXI Legislatura del H. Congreso del Estado de Oaxaca/Universidad Autónoma Metropolitana, 2010.

Jiménez Calvente, Teresa. "Fernando el Católico. Un héroe épico con vocación mesiánica.” En La imagen de Fernando el Católico en la historia, la literatura y el arte. Coord. de Aurora Egido y José Enrique Laplana Gil, 131-170. Zaragoza: Institución Fernando el Católico, 2014.

Juárez Nieto, Carlos. “Ayuntamiento y oligarquía en Valladolid de Michoacán (18081824).” En El poder y el dinero. Grupos y regiones mexicanos en el siglo XIX. Coord. de Beatriz Rojas, 53-70. México: Instituto de Investigaciones Dr. José María Luis Mora, 1999.

Landavazo, Marco Antonio. Nacionalismo y violencia en la Independencia de México. Toluca: Fondo Editorial Estado de México, 2012.

Landavazo, Marco Antonio. La máscara de Fernando VII. Discurso e imaginario monárquicos en una época de crisis. Nueva España, 1808-1822. México: El Colegio de México/Universidad Michoacana de San Nicolás de Hidalgo/El Colegio de Michoacán, 2011.

Landavazo, Marco Antonio. "Imaginarios encontrados. El antiespañolismo en México en los siglos xix y xx.” Tzintzun. Revista de Estudios Históricos, n. 42 (julio-diciembre 2005): 33-48.

Landavazo, Marco Antonio. "La sacralización del rey. Fernando VII, la insurgencia novohispana y el derecho divino de los reyes.” Revista de Indias, v. LXI, n. 221 (2001): 67-90, https://doi.org/10.3989/revindias.2001.i221.483 
Lida, Clara Eugenia. "¿Qué son las clases populares? Los modelos europeos frente al caso español en el siglo xix." Historia Social, n. 27 (1997): 3-21.

López Bárcenas, Francisco. "Los pueblos mixtecos en la Guerra de Independencia." En La guerra de Independencia en Oaxaca. Nuevas perspectivas. Coord. de Carlos Sánchez Silva, 103-124. Oaxaca: Universidad Autónoma Benito Juárez de Oaxaca/Comisión Permanente de Cultura de la LXI Legislatura del H. Congreso del Estado de Oaxaca/Universidad Autónoma Metropolitana, 2010.

Moreno Gutiérrez, Rodrigo. La Trigarancia. Fuerzas armadas en la consumación de la Independencia. Nueva España, 1820-1821. México: Universidad Nacional Autónoma de México, Instituto de Investigaciones Históricas/Fideicomiso Felipe Teixidor y Monserrat Alfau de Teixidor, 2016.

Ortiz Escamilla, Juan. Calleja. Guerra, botín y fortuna. Xalapa; Zamora: Universidad Veracruzana/El Colegio de Michoacán, 2017.

Ortiz Escamilla, Juan. Guerra y gobierno. Los pueblos y la Independencia de México, 1808-1825. México: El Colegio de México/Instituto de Investigaciones Dr. José María Luis Mora, 2014.

Pani, Erika. "De coyotes y gallinas. Hispanidad, identidad nacional y comunidad política durante la expulsión de españoles." Revista de Indias, v. LXIII, n. 228 (2003): 355-374, https://doi.org/10.3989/revindias.2003.i228.442

Pardo Hernández, Claudia Patricia. "Tres expulsiones fallidas de la ciudad de México entre 1828 y 1847: los españoles, los franceses y los estadounidenses." Ulúa, n. 4 (julio diciembre 2004): 9-32.

Pérez Vejo, Tomás. "Cuando los españoles estuvieron a punto de dejar de ser gachupines.” En Enemigos íntimos. España, lo español y los españoles en la configuración nacional hispanoamericana 1810-1910. Coord. de Tomás Pérez Vejo, 213-244. México: El Colegio de México, 2011.

Pi-Suñer Llorens, Antonia. La deuda española en México. Diplomacia en torno a un problema financiero, 1821-1890. México: El Colegio de México/Universidad Nacional Autónoma de México, Facultad de Filosofía y Letras, 2006.

Plasencia de la Parra, Enrique. Independencia y nacionalismo a la luz del discurso conmemorativo (1825-1867). México: Consejo Nacional para la Cultura y las Artes, 1991.

Rodríguez, Jaime E. Nosotros somos ahora los verdaderos españoles, v. I. México: El Colegio de Michoacán/Instituto de Investigaciones Dr. José María Luis Mora, 2012. Rojas, Beatriz. “Aguascalientes y Zacatecas, 1821-1835. ¿Una política compartida?” En El poder y el dinero. Grupos y regiones mexicanos en el siglo XIX. Coord. de Beatriz Rojas, 93-119. México: Instituto de Investigaciones Dr. José María Luis Mora, 1999. Ruiz de Gordejuela Urquijo, Jesús. La expulsión de los españoles de México y su destino incierto, 1821-1836. Sevilla: Consejo Superior de Investigaciones Científicas/ 
Escuela de Estudios Hispano-Americanos/Universidad de Sevilla/Diputación de Sevilla, 2006.

Sánchez Silva, Carlos. "Los cabildos civil y eclesiástico de la ciudad de Oaxaca ante la invasión insurgente, 1812-1814." En La Guerra de Independencia en Oaxaca. Nuevas perspectivas. Coord. de Carlos Sánchez Silva, 63-82. Oaxaca: Universidad Autónoma Benito Juárez de Oaxaca/Comisión Permanente de Cultura de la LXI Legislatura del H. Congreso del Estado de Oaxaca/Universidad Autónoma Metropolitana, 2010.

Sims, Harold. La expulsión de los españoles de México (1821-1828). México: Secretaría de Educación Pública, 1985.

Sims, Harold. Descolonización en México. El conflicto entre mexicanos y españoles (1821-1831). México: Fondo de Cultura Económica, 1982.

Sims, Harold. La reconquista de México, la historia de los atentados españoles, 18211830. México: Fondo de Cultura Económica, 1980.

Soto Estrada, Miguel. "Imágenes y estereotipos durante la expulsión de los españoles de México.” En México y España en el siglo XIX. Diplomacia, relaciones triangulares e imaginarios nacionales. Coord. de Agustín Sánchez Andrés y Raúl Figueroa Esquer. Morelia: Universidad Michoacana de San Nicolás de Hidalgo/ Instituto de Investigaciones Históricas/Instituto Tecnológico Autónomo de México, 2003.

Taylor, William B. Embriaguez, homicidio y rebelión en las poblaciones coloniales mexicanas. México: Fondo de Cultura Económica, 1987.

Tella Torcuato, Di. "Las clases peligrosas a comienzos del siglo Xıx en México." Desarrollo Económico, v. 12, n. 48 (enero-marzo 1973): 761-791, https://doi. org/10.2307/3466303

Torres Puga, Gabriel. Opinión pública y censura en Nueva España. Indicios de un silencio insoportable 1767-1794. México: El Colegio de México, 2010.

Young, Eric Van. La otra rebelión. La lucha por la Independencia de México, 18101821. México: Fondo de Cultura Económica, 2010.

\section{SOBRE EL AUTOR}

Candidato a Doctor en Historia por la Universidad Autónoma Metropolitana-Iztapalapa. Sus líneas de especialidad son historia de la violencia, militar y de la prensa. Autor del libro Guerrilla, violencia y racismo en la guerra entre México y Estados Unidos (1846-1848), México, Universidad Autónoma Metropolitana, en prensa. 